\title{
Complementary feeding practices and associated factors in Damot Weydie District, Welayta zone, South Ethiopia
}

\author{
Bereket Epheson ${ }^{1 \dagger}$, Zewdie Birhanu2 ${ }^{2}$ Dessalegn Tamiru ${ }^{3}$ and Garumma Tolu Feyissa ${ }^{2^{* \dagger}}$
}

\begin{abstract}
Background: Each year, more than millions of under-five children die due to under-nutrition, and many of these deaths are associated with inappropriate feeding practices. This study aimed to assess complementary feeding practices in Damot Weydie District, South Ethiopia.

Methods: A community-based cross-sectional study was conducted among four-hundred and one mothers who had children aged 6-23 months in Damot Weydie District. A pretested structured questionnaire was used to collect data using a face-to-face interview. Data were entered into Epi-Data version 3.1 and analysis was done by using Statistical Package for Social Sciences (SPSS) version 20. Multivariable logistic regressions were conducted to determine independent factors associated with complementary feeding practices.
\end{abstract}

Results: More than half (50.6\%) of children were given complementary foods at six months of age. Only $8.5 \%$ of young children aged 6-23 months were fed with appropriate complementary foods. The proportion of mothers who reported that they know that a baby of 6-23 months old should be fed two or three times was only $75.8 \%$. Governmentemployed mothers (adjusted odds ratio $(A O R)=0.14(0.04,0.50)$ and mothers who attended postnatal care $(A O R=0$. $19(0.05,0.70)$ were less likely to practice inappropriate complementary feeding. Mothers having children with birth intervals less than 35 months were more likely to practice inappropriate complementary feeding when compared to mothers of children with birth intervals greater than 35 months ( $A O R=2.67(1.22,5.83)$.

Conclusions: Considerable proportions of infants and young children were not appropriately fed with complementary foods as per WHO recommendations. Being a government employee mother, attending postnatal care and having a child with birth interval greater than 3 years were associated with appropriate complementary feeding. Therefore, it is important to encourage postnatal care utilization and incorporate complementary feeding advice during postnatal visits. It is critical to raise the awareness of the community about optimal complementary feeding practices with special attention to unemployed and less educated mothers. Additionally, inter-sectoral collaboration should be strengthened to increase the variety of food groups available.

Keywords: Complementary feeding, Dietary diversity, Meal frequency, Ethiopia

\footnotetext{
* Correspondence: garummatolu@yahoo.com

${ }^{\dagger}$ Equal contributors

${ }^{2}$ Jimma University, Department of Health, Behaviour and Society, Jimma

University Institute of Health, Jimma, Ethiopia

Full list of author information is available at the end of the article
} 


\section{Background}

According to the Ethiopian Demographic and Health Survey (DHS) data of 2016, 38\% of under-five children are stunted and $10 \%$ of them are wasted [1]. Global evidence suggests that $15 \%$ deaths in under-five children can be averted if populations could access evidencebased interventions with $90 \%$ coverage [2].

The World Health Organization (WHO), at its 54th health assembly urged member states 'to strengthen activities and develop new approaches to protect, promote and support exclusive breastfeeding for six months' (pp.2) [3] and 'to provide safe and appropriate complementary foods, with continued breastfeeding for up to two years of age or beyond, emphasizing channels of social dissemination of these concepts in order to lead communities to adhere to these practices (pp.3) [3].

The WHO defines complementary feeding as "the process starting when breast milk alone is no longer sufficient to meet the nutritional requirements of infants, and therefore other foods and liquids are needed, along with breast milk." pp.8 [4]. Starting complementary feeding too soon and delaying for too long is also not advisable. The early exposure of infants to microbial pathogens potentially contaminating complementary foods and fluids puts them at increased risk of diarrheal diseases and consequently malnutrition and breast milk alone may not provide enough energy and nutrients and may lead to growth faltering and malnutrition respectively [5]. Therefore, the WHO recommends that complementary feeding should commence at six months after birth [4].

The frequency of meals required by an infant or a young child in a day depends on the amount of energy that the young infant or the child needs, the amount that a child can eat at each meal and the energy density of the food offered. Breastfed children need only nonliquid foods, whereas. Non-breastfed children should get both milk and solid or semi-solid foods $[6,7]$. Appropriate feeding of children aged 6-23 months is multidimensional. Hence it is essential to have a composite indicator that tracks the extent to which these multiple dimensions of adequate child feeding are being met. The minimum acceptable diet is an indicator that combines standards of dietary diversity and feeding frequency and breastfeeding status. It helps to track progress at simultaneously improving the key quality and quantity dimensions of children's diets [7, 8].

A complementary feeding that is provided based on the WHO recommendations promotes growth of the child and prevents stunting among children between 6 and 23 months of age [9]. However, according to the Ethiopian DHS data of 2016 only 7 seven percent of children aged 6-23 months were reported to have met the minimum acceptable diet [1]. Few localized studies in Ethiopia, indicated that complementary feeding practices were inadequate $[10,11]$. Still there are variations across the study findings, especially with respect to timing of initiation of complementary feeding [10-12]. Given that there are variations in feeding practices across study settings, this study aimed to assess complementary feeding practices in Damot Weydie District, which is found in Southern Nations and Nationalities People's Representative (SNNPR).

\section{Methods \\ Study setting and design}

This community-based cross-sectional study was conducted from March to April 2014 in Damot Weydie District, which is located at $26 \mathrm{Km}$ to the east of the zonal capital of Welayta Sodo and $368 \mathrm{Km}$ from Addis Ababa. Damot Weydie is one of the rural districts in Welayta Zone. The district has 25 kebeles (the lowest administrative level). All the kebeles are accessible in both dry and rainy seasons. There is one main road which connects the district with zonal and regional towns. Based on projection from 2007 population and housing census report, the total population in $2013 / 14$ was estimated to be 112,065 where 55,696 are males and 56,369 are females [13]. Most of the residents depend on traditional subsistence agriculture for living. The main crops produced in the area are maize and sorghum (Weyde District D. 2013.Health office, Annual Report[unpublished]).

\section{Target population}

The source population for the current study was all children aged 6-23 months with their mothers/care givers residing in Damot Weydie District. Those mothers and children who do not meet the inclusion criteria (children less 6 months or above 2 years of age) and mothers who were unable to respond due to some reasons were excluded from the study.

Sample size and sampling technique.

Sample size was determined by using single proportions formula with the assumptions of $\mathrm{P}$ (minimum meal frequency of infant and young child) of 48.9\% [11] in Southerns Nations and Nationalities Peoples Representative (SNNPR) and a 95\% confidence interval with margin of error $5 \%$. With these assumptions, a sample size of four hundred and four was obtained. Eight kebeles were randomly selected from the list of 25 kebeles. The sample was then allocated for the selected kebeles by proportionally based on the population size of each kebele. Finally, study participants were selected by using simple random sampling from each selected kebele. The eligible target children were selected according to the sampling frame created based on record obtained from Health 
Extension Worker's (HEW's) family folder and from each household of eligible child aged 6-23 months and who had mother/care giver at the time of the study.

\section{Study variables}

Dependent variable: The dependent variable was complementary feeding practices.

Independent variable: The independent variables of the study were:

a. Socio-economic and demographic characteristics such as age, marital status, family size, educational status, husband educational status, occupational status, family wealth,

b. Maternal health service and related characteristics such as parity, ANC visit, place of delivery, PNC visit, knowledge of mothers, water supply, source/ access to information

c. Child related characteristics such as age, sex, birth order and birth interval.

\section{Data collection tool and measurement}

The structured interviewer-administered questionnaire was used to collect data. The questionnaire was developed in English, translated into Wolaita Doonaa (local language), and back translated to English to check its conceptual equivalence by a person who can speak both languages. A 24-h dietary recall method, which is the most widely used time-period for collecting dietary information, was used to collect dietary information. The quality of the data was assured through a pre-test conducted in a similar setting (Sodo Zuria). The consistency and flow of the questionnaire was checked during the pretest. Training was given for data collectors and supervisors. Completed questionnaires were cross-checked by data collection supervisors daily.

\section{Data processing and analysis}

Data were entered into Epi-Data 3.1 statistical software, and then exported to Statistical Package for Social Sciences (SPSS) version 20 for analysis. Descriptive analysis such as frequencies, proportions, and means were calculated. Binary logistic regressions were used to determine the strength of association between independent and dependent variables using odds ratios (OR) and 95\% confidence intervals. Variables with $P \leq 0.25$ in bivariate analysis were selected for multivariable analysis. In multivariate logistic regression analysis, both crude and adjusted odds ratios were calculated to identify independent factors associated with appropriate complementary feeding practices and $P$ value $\leq 0.05$ was considered as significant.

In this study, timely introduction of complementary feeding was defined as the proportion of children aged
6-23 months who started complementary foods at 6th month. Minimum dietary diversity was defined as the proportion of children aged 6-23 months who received foods from four or more food groups from seven food groups. The seven food groups used for tabulation of this indicator were grains, roots and tubers; legumes and nuts; dairy products (milk, yogurt, cheese); flesh foods (meat, chicken and liver/organ meats); eggs; vitamin 'A' rich fruits and vegetables; and other fruits and vegetables.

Table 1 Socio demographic characteristics of mothers of study participants, Damot Weydie district, Welayta zone, Ethiopia, 2014

\begin{tabular}{|c|c|c|}
\hline Variables & Categories & Frequency (\%) \\
\hline \multirow[t]{3}{*}{ Ethnicity } & Welayta & 396(98.8) \\
\hline & Amhara & $4(1)$ \\
\hline & Gurage & $1(0.2)$ \\
\hline \multirow[t]{3}{*}{ Religion } & Protestant & 319(79.6) \\
\hline & Orthodox & $73(18.2)$ \\
\hline & Catholic & $9(2.2)$ \\
\hline \multirow[t]{3}{*}{ Husband education } & No education & 179(44.6) \\
\hline & Primary & 124(30.9) \\
\hline & Secondary + & $98(24.4)$ \\
\hline \multirow[t]{4}{*}{ Age of mother } & 20-24 years & $59(14.7)$ \\
\hline & $25-29$ years & 115(28.7) \\
\hline & 30-34 years & $121(30.2)$ \\
\hline & $35-40$ years & $106(26.4)$ \\
\hline \multirow[t]{3}{*}{ Marital status } & Single & $7(1.7)$ \\
\hline & Married & 392(97.8) \\
\hline & Widowed & $2(0.5)$ \\
\hline \multirow[t]{2}{*}{ Family size } & Below 5 & 186(46.4) \\
\hline & Above 5 & 215(53.6) \\
\hline \multirow[t]{3}{*}{ Mother occupation } & House wife & 268 \\
\hline & Government employee & 15 \\
\hline & Others $^{\mathrm{a}}$ & 118 \\
\hline \multirow[t]{5}{*}{ Household wealth index } & Poorest & 87 \\
\hline & Poorer & 73 \\
\hline & Middle & 82 \\
\hline & Richer & 79 \\
\hline & Richest & 80 \\
\hline \multirow[t]{2}{*}{ Place delivery } & Home & 180 \\
\hline & Health institution & 221 \\
\hline \multirow[t]{3}{*}{ Age of child } & 6-11 months & 129 \\
\hline & 12-17 months & 176 \\
\hline & $18-23$ months & 96 \\
\hline \multirow[t]{2}{*}{ Sex of child } & Male & 207 \\
\hline & Female & 194 \\
\hline
\end{tabular}

${ }^{a}$ Students, Private business, Farmer 
Table 2 Caregivers' knowledge of complementary feeding practices at Damot Weydie district, Welayta zone, SNNPRS, 2014

\begin{tabular}{ll}
\hline Knowledge items & Frequency (\%) \\
\hline Heard about complementary feeding & $389(97)$ \\
Heard when to start complementary food & $388(96.8)$ \\
Know what types of foods to feed young children & $384(95.8)$ \\
Know how to feed young children & $376(93.8)$ \\
Know when to start complementary food & $280(69.8)$ \\
Know baby of 6-23 months should eat 2/3 times & $304(75.8)$ \\
Know feeding anything from a bottle not good & $165(41.1)$ \\
Know thicker porridge do not chock the child & $328(81.8)$ \\
Know hand washing before food preparation & $387(96.5)$ \\
Know hand washing with soap/ash after toilet & $369(92)$ \\
\hline
\end{tabular}

Minimum meal frequency was defined as the proportion of breastfed and non-breastfed children aged 623 months who received solid, semi-solid, or soft foods the minimum number of times or more. For breastfed children, the minimum number of times varies with age (2 times if 6-8 months and 3 times if 9-23 months). The minimum acceptable diet was defined as the proportion of breastfed children aged 6-23 months who had at least the minimum dietary diversity and the minimum meal frequency during the previous day [1].

\section{Results}

Four-hundred and one caregivers participated in the study with a response rate of $99.3 \%$. Majority of participants $(97.8 \%)$ were married. The mean $( \pm$ SD) age of the caregivers was $30.26( \pm 4.98)$ years with the range of 21-40 years. More than half of caregivers (55.1\%) had no education. The mean age of children was $1.16( \pm 0.38$ years) (Table 1$)$.

The current study showed that majority (97\%) of mothers had heard about complementary feeding practices and 165 (41.15\%) knew about the harmful effect of bottle-feeding. The mean knowledge score about complementary feeding of study participants was $7.95(\mathrm{SD}=$ 1.327) (Table 2). One hundred and twenty-six (31.4\%) mothers provided food made from grains while $177(44.1 \%)$ of them gave dairy products for their children. Small number of caregivers (15.7\%) fed their children in the previous day. Only 38 (9.5\%) of children ate foods that contained Vitamin A rich fruits and vegetables during the day or night. Overall, half of the children (50.6\%) aged 6-23 months consumed some solid or semi-solid foods during the day or night (Fig. 1).

Our study showed that only $8.5 \%$ of young children aged 6-23 months were fed with appropriate complementary foods. More than half (50.6\%) of mothers introduced complementary foods at 6 months of age as per WHO recommendation. Nearly, 396(98.8\%) children received breast milk during the 24 -h period and $189(47.1 \%)$ were fed at least the minimum number of times. In total, 34 (8.5\%) of the children were appropriately fed with complementary foods (Fig. 2).

In the bivariate analysis, postnatal care, occupational status of the mother, childbirth interval and hearing about complementary feeding from health workers were found to be associated with complementary

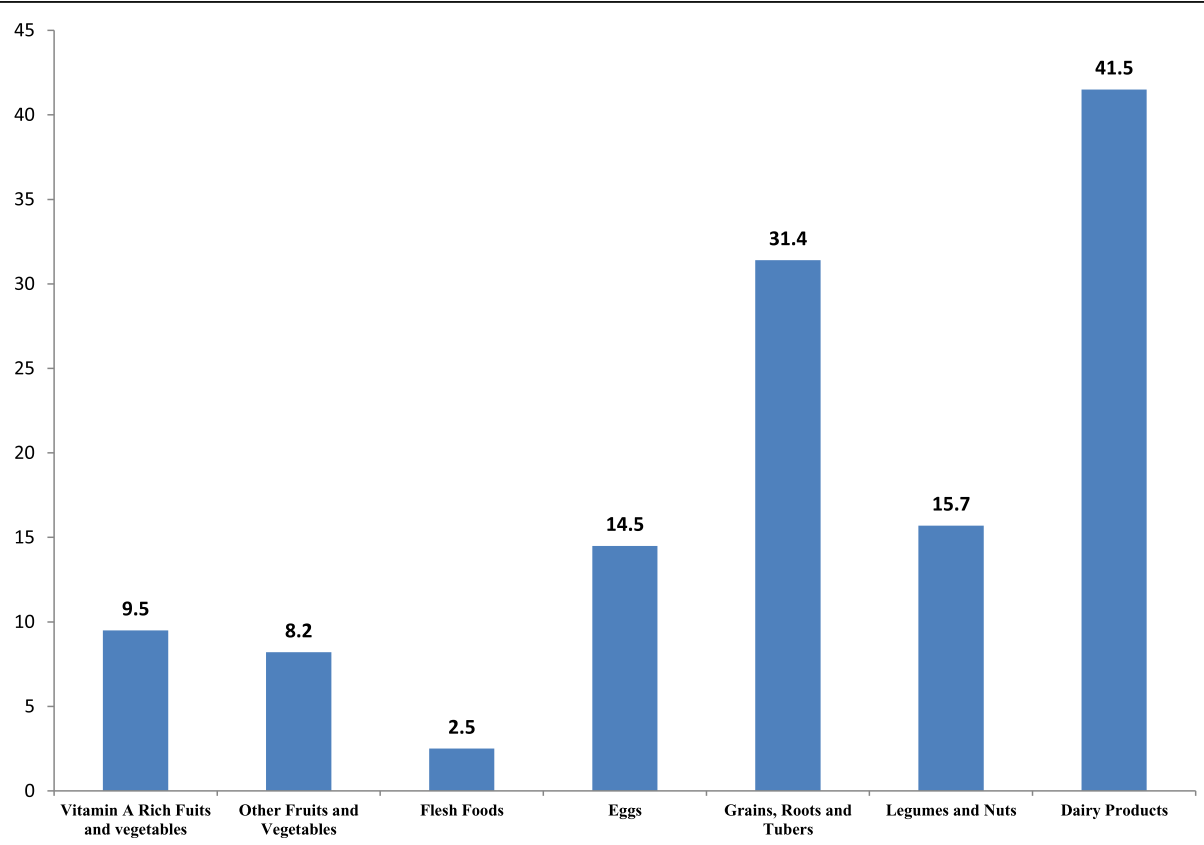

Fig. 1 Types of foods given to children aged 6-23 months in Damot Weydie district, Welayta zone, SNNPRS, 2014 


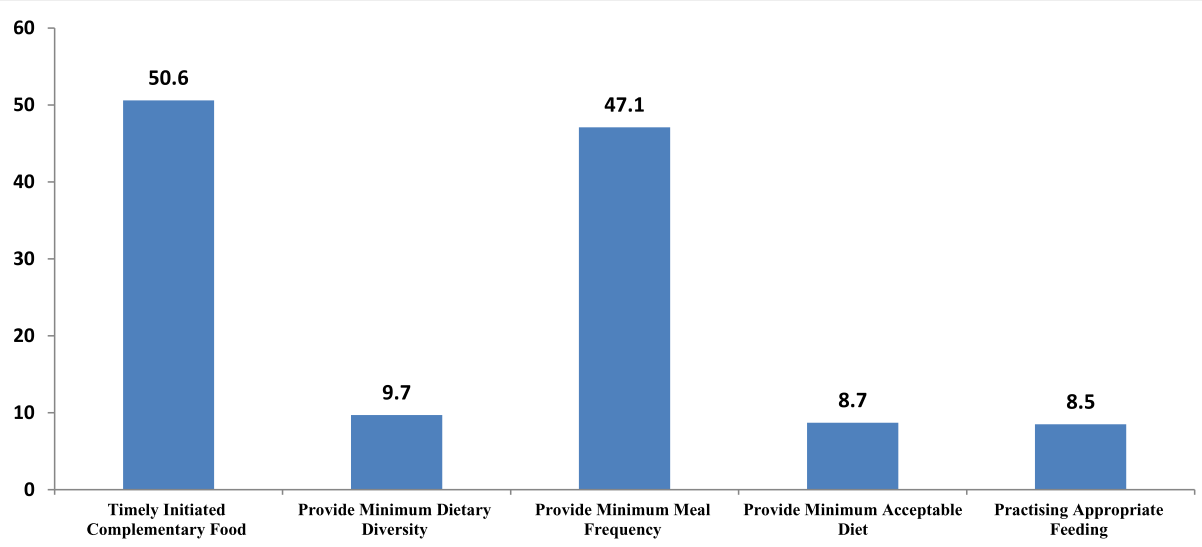

Fig. 2 Proportion of complementary feeding practices of infant and young children (6-23 months) in Damot Weydie District, Welayta zone, SNNPRS, 2014

feeding practices (data not shown). In multivariate logistic regression analysis, mother's occupation, preceding birth interval of the child and postnatal care were independent factors associated with appropriate complementary feeding practices. Mothers who were government employees were $85.1 \%$ less likely to practice inappropriate complementary feeding when compared to those of housewives (AOR $=0.14 \quad(0.04,0.50)$. Children born with less than 35 months ( $<3$ years) preceding birth intervals were 2.67 times more likely to be fed with inappropriate complementary feeding when compared to children born with greater than 35 months $(<3$ years $)$ birth intervals $(\mathrm{AOR}=2.67$ (1.22, 5.83). Mothers who attended postnatal care were $80.2 \%$ less likely to practice inappropriate complementary feeding compared to mothers who did not attend $(\mathrm{AOR}=0.19(0.05,0.70)$ (Table 3$)$.

\section{Discussion}

The results of this study revealed that complementary feeding was timely introduced to $50.6 \%$ of infants and young children included in this study. This finding is in agreement with the findings of the study conducted in Eastern Ethiopia, which reported a prevalence of $54 \%$ [10]. However, it is slightly lower when compared to the finding of a previous study conducted in Northern Ethiopia, which reported a prevalence of $62.8 \%$ [12]. In addition, our finding was lower when compared to the findings from other countries like United Arab Emirates (83.5\%) [9], Tanzania (92.3\%) [14], coastal South India (77.5\%) [15] and Nepal (70\%) [16]. Among children aged 6-23 months, 9.7\% received foods from at least four food groups or more (minimum dietary diversity). It was higher than the regional state data of the Southern Nations and Nationalities People's Representatives (SNNPR) regional state which was $2.5 \%$. The relatively higher proportion might be due to practice change with time, and the contribution of community-based nutrition interventions led by health extension workers.

About $47.1 \%$ of infants and young children (623 months) were fed at least with the minimum required meal frequency. This finding is low when compared to findings from Nepal, which was $82 \%$ [16]. The difference

Table 3 Complementary feeding practices and associated factors in Damot Weydie district, Welayta zone, SNNPRS, 2014

\begin{tabular}{|c|c|c|c|c|c|}
\hline \multirow[t]{2}{*}{ Characteristics } & & \multicolumn{4}{|c|}{ Complementary Feeding Practices } \\
\hline & & Appropriate & Inappropriate & COR $(95 \% \mathrm{Cl})$ & AOR $(95 \% \mathrm{Cl})$ \\
\hline \multirow[t]{3}{*}{ Mother's occupation } & House wife & 7.5 & 92.5 & 1 & 1 \\
\hline & Government employee & 33.3 & 66.7 & $0.16(0.05,0.52)$ & $0.14(0.04,0.50)++$ \\
\hline & Others $^{a}$ & 7.6 & 92.4 & $0.97(0.43,2.21)$ & $0.72(0.31,1.70)$ \\
\hline \multirow[t]{2}{*}{ Preceding Birth interval } & $<35$ months & 6.8 & 93.2 & $2.29(1.09,4.78)$ & $2.67(1.22,5.83)+$ \\
\hline & $35^{+}$months & 14.3 & 85.7 & 1 & 1 \\
\hline \multirow[t]{2}{*}{ Attending PNC } & Yes & 10.4) & 89.6 & $0.25(0.07,0.85)$ & $0.19(0.05,0.70)+$ \\
\hline & No & 2.9 & 97.1 & 1 & 1 \\
\hline \multirow[t]{2}{*}{ Sex of the child } & Male & 10.1 & 89.9 & $0.63(0.30,1.30)$ & $0.50(0.23,1.07)$ \\
\hline & Female & 6.7 & 93.3 & 1 & 1 \\
\hline
\end{tabular}

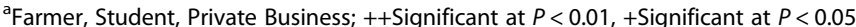

COR Crude odds ratio, AOR Adjusted odds ratio, $\mathrm{Cl}$ Confidence Interval 
might be due to low maternal educational status about optimal child feeding practices in our study area. The proportion of mothers who knew that a baby of $6-$ 23 months old should be fed two or three times was only $75.8 \%$. This finding underscore that it is essential to raise the awareness of the community regarding the optimal frequency of complementary feeding.

The minimum acceptable diet (either four or more food groups and minimum meal frequency) reported in this study $(8.7 \%)$ was relatively higher when compared to findings of other studies from southern Ethiopia [12]. This might be due to the recent initiation of intersectoral collaboration of nutrition programs. However, it is comparable to the 2016 national level data of Ethiopia (7\%) [1].

Finding of this study showed that a small proportion of caregivers $(8.5 \%)$ were practicing appropriate complementary feeding which was lower than findings from Zambia (25.1\%) [17]. This might be due to poor socioeconomic status and lower maternal literacy, or due to unavailability of the food varieties, which may make mothers incapable of fulfilling dietary diversity and frequency of meal.

Government-employed mothers were less likely to practice inappropriate complementary feeding when compared to those mothers who were housewives, which is similar with findings of the study from Nepal [16]. This might be due to the fact that women's employment increases household income and access to health information with consequent benefit to household nutrition in general and child feeding practices in particular [1820]. This study also showed that higher birth intervals preceding the child (more than 3 years) were significantly associated with appropriate feeding practices, which is in agreement with the findings from Nepal and other developing countries [16, 18, 19]. This might be due to availability of sufficient time to give care for a child before giving other birth.

Our findings also indicated that caregivers who attended postnatal care were more likely to practice appropriate complementary feeding when compared to those care givers who did not attend postnatal care. This result was in congruent with the findings from Northwestern Tigray, Tanzania, India and Nepal [14-16, 21]. This might be due to the result of counseling that the mothers receive from health professionals during their postnatal visits. However, this study showed that there was no statistically significant association between maternal education and appropriate complementary feeding practice and it disagrees with the study reports from Nepal and India $[15,16]$.

Even though this study addressed complementary feeding practice in Damot District, it should be interpreted with the following limitations. Child feeding practices were age-specific with narrow age ranges and typically assessed by caregivers' report or recall which can lead to recall bias. Seasonal variations might affect the food groups consumed by the infants and young children during the time of the interview. The crosssectional nature of the study itself poses difficulty in establishing cause-effect relationship.

\section{Conclusions}

Significant proportions of children were not appropriately fed with complementary foods as per the WHO recommendations. Being a government employee mother, attending postnatal care and a higher ( $>3$ years) birth interval preceding the infant and young child were associated with appropriate complementary feeding. This implies that unemployed mothers and mothers who did not attend postnatal care were less likely to adhere to complementary feeding practices as per the WHO recommendations. Therefore, it is important to encourage postnatal care utilization and incorporate complementary feeding advice during postnatal visits. In addition, unemployed and less educated mothers should be given special attention in teaching about complementary feeding practices. The proportion of mothers who reported that they know that a baby of 6-23 months old should be fed two or three times was only $75.8 \%$. Therefore, it is essential to raise the awareness of the community regarding the optimal complementary feeding practices, with special attention on frequency of feeding. Additionally, inter-sectoral collaboration should be strengthened to increase the variety of food groups.

\section{Abbreviations}

ANC: Antenatal Care; AOR: Adjusted Odds Ratio; COR: Crude Odds Ratio; EDHS: Ethiopian Demographic and Health Survey; SNNPRS: South Nations Nationalities and Peoples Regional State; SPPSS: Statistical Package for Social Sciences

\section{Acknowledgments}

We would like to thank Jimma University for financial and technical support. We would also like to thank data collectors and study participants.

\section{Funding}

This study was funded by Jimma University. The views presented in the article are of the author and not necessarily express the views of the funding organization.

\section{Availability of data and materials}

The dataset used for this study, cannot be shared and in the future interested parties may request the approval to access the data by writing to Jimma University Institutional Review Board.

\section{Authors' contributions}

$\mathrm{BE}, \mathrm{ZB}, \mathrm{DT}$ and GTF made a substantial contribution to the design, conduct, analyses, interpretation and report writing. All authors read and approved the final version of the manuscript.

\section{Ethics approval and consent to participate}

Ethical clearance was obtained from Institutional Review Board (IRB) of Jimma University Institute of Health and permission letter was also obtained from Welayta Zone Health Office and Damot Weydie District Health Office. Participants were from the rural and prominent proportion of them could not read and write. Hence, based on the consent procedure approved by the IRB, 
oral informed consent was obtained from each respondent after explanation of the study objectives. Confidentiality was maintained by omitting their personal identifications.

\section{Consent for publication}

Not applicable.

\section{Competing interest}

The authors declare that they have no competing interests.

\section{Publisher's Note}

Springer Nature remains neutral with regard to jurisdictional claims in published maps and institutional affiliations.

\section{Author details}

${ }^{1}$ Regional Health Bureau of the Southern Nations, Nationalities and Peoples' Region, Hawassa, Ethiopia. ${ }^{2}$ Jimma University, Department of Health, Behaviour and Society, Jimma University Institute of Health, Jimma, Ethiopia. ${ }^{3}$ Jimma University, Department of Population and Family Health, Jimma University Institute of Health, Jimma, Ethiopia.

\section{Received: 4 August 2017 Accepted: 1 March 2018}

Published online: 27 March 2018

\section{References}

1. Central Statistical Agency (CSA) [Ethiopia] and ICF. 2016. Ethiopia demographic and health survey 2016: Key Indicators Report. Addis Ababa, Ethiopia, and Rockville, Maryland, USA. CSA and ICF.

2. Bhutta ZA, Das JK, Rizvi A, Gaffey MF, Walker N, Horton S, et al. Evidencebased interventions for improvement of maternal and child nutrition: what can be done and at what cost? Lancet. 2013;382(9890):452-77.

3. World Health Organization. Fifty-Fourth World Health Assembly. Global Strategy for Infant and Young Child Feeding. The optimal duration of exclusive breastfeeding. Geneva, Switzerland: World Health Organization. 2001.

4. World Health Organization. Guiding principles for feeding non-breastfed children 6-24 months of age; accessed on august 1, 2017 from www.who. int/nutrition/publications/guiding_principles_compfeeding_breastfed.pdf

5. Cattaneo A, Fallon M, Kewitz G, Mikiel-Kostyra K, Robertson A, Yngve A. Infant and young child feeding: standard recommendations for the European Union. European Commission: Directoriate Public Health and Risk Assessment, Luxemburg; 2006.

6. Shi L, Zhang J. Recent evidence of the effectiveness of educational interventions for improving complementary feeding practices in developing countries. J Trop Pediatr. 2010 Apr 17;57(2):91-8

7. World Health Organization (WHO). Indicators for assessing infant and young child feeding practices: conclusions of a consensus meeting held 6-8 November 2007 in Washington DC, USA. World Health Organization (WHO); 2008

8. Obodoechi ljeoma F, Dogra A, Dharman V, Veliah G, Kosalam K. Infant and Young Child (6-35 Months) Feeding Practices (IYCF): A Comparative Study of Three States in India. Public Health Research Series.p.34.

9. Radwan H. Patterns and determinants of breastfeeding and complementary feeding practices of Emirati mothers in the United Arab Emirates. BMC Public Health. 2013 Feb 25;13(1):171.

10. Abera K. Infant and young child feeding practices among mothers living in Harar, Ethiopia. Harar bulletin of Health Sciences 2012:4:66-78.

11. Gibson RS, Abebe Y, Hambidge KM, Arbide I, Teshome A, Stoecker BJ. Inadequate feeding practices and impaired growth among children from subsistence farming households in Sidama, southern Ethiopia. Maternal \& child nutrition. 2009:5(3):260-75.

12. Shumey A, Demissie M, Berhane Y. Timely initiation of complementary feeding and associated factors among children aged 6 to 12 months in Northern Ethiopia: an institution-based cross-sectional study. BMC Public Health. 2013 2013/11/06;13(1):1050.

13. Federal Democratic Republic of Ethiopia Population Census Commission. Summary and statistical report of the 2007 population and housing census. Ethiopia: Addis Ababa; 2008 Dec.

14. Victor R, Baines SK, Agho KE, Dibley MJ. Factors associated with inappropriate complementary feeding practices among children aged 6-23 months in Tanzania. Maternal \& child nutrition. 2014 Oct 1;10(4):545-61.
15. Rao S, Swathi PM, Unnikrishnan B, Hegde A. Study of complementary feeding practices among mothers of children aged six months to two years-A study from coastal south India. The Australasian medical journal. 2011:4(5):252.

16. Khanal V, Sauer K, Zhao Y. Determinants of complementary feeding practices among Nepalese children aged 6-23 months: findings from demographic and health survey 2011. BMC Pediatr. 2013 Aug 28;13(1):131.

17. Ali D, Rawat R, Subandoro A, Menon P. Infant and young child feeding practices in Ethiopia and Zambia and their association with child nutrition: analysis of demographic and health survey data. African Journal of Food, Agriculture, Nutrition and Development. 2012;12:5895-914.

18. Ruel MT, Alderman H, Maternal and Child Nutrition Study Group. Nutritionsensitive interventions and programmes: How can they help to accelerate progress in improving maternal and child nutrition? The Lancet. 2013 Aug 16:382(9891):536-51.

19. Senarath U, Agho KE, Akram DE, Godakandage SS, Hazir T, Jayawickrama H, et al. Comparisons of complementary feeding indicators and associated factors in children aged 6-23 months across five South Asian countries. Maternal \& child nutrition. 2012 Jan 1;8(s1):89-106

20. Hazir T, Senarath U, Agho K, Akram DS, Kazmi N, Abbasi S, Dibley MJ. Determinants of inappropriate timing of introducing solid, semi-solid or soft food to infants in Pakistan: Secondary data analysis of Demographic and Health Survey 2006-2007. Maternal \& child nutrition. 2012;8(s1):78-88.

21. Mulugeta A, Hagos F, Kruseman G, Linderhof V, Stoecker B, Abraha Z, Yohannes M, Samuel GG. Factors contributing to child Malnutrition in Tigray. Northern Ethiopia. 2005;20:96-105.

\section{Submit your next manuscript to BioMed Central and we will help you at every step:}

- We accept pre-submission inquiries

- Our selector tool helps you to find the most relevant journal

- We provide round the clock customer support

- Convenient online submission

- Thorough peer review

- Inclusion in PubMed and all major indexing services

- Maximum visibility for your research

Submit your manuscript at www.biomedcentral.com/submit
C Biomed Central 